\title{
El efecto de las remesas familiares en el bienestar de los hogares guatemaltecos
}

\author{
Sibyl Italia Pineda Salazar \\ Instituto de Investigaciones Económicas y Sociales (IDIES), Universidad Rafael Landívar, Ciudad de Guatemala. Correo electrónico: \\ sipineda@url.edu.gt, sibylpineda@gmail.com
}

\section{Recibido: mayo de 2008 / Aceptado: junio de 2008}

EL PRESENTE ESTUDIO TIENE COMO OBJETIVO MEDIR EL EFECTO QUE HAN tenido las remesas familiares en el bienestar de los hogares guatemaltecos. El análisis se realizó a través de los datos proporcionados por el Instituto Nacional de Estadística (INE) en su Encuesta Nacional de Condiciones de Vida (ENCOVI) del año 2006.

Para determinar el efecto que tienen estos flujos, se aplicó un modelo econométrico ${ }^{1}$ planteado por Adams (2004) que utiliza el Agregado de Consumo como medida de bienestar.

En base a las estimaciones derivadas, se logró determinar que las remesas familiares han generado una disminución en la incidencia, la brecha y severidad de la pobreza en el país. Asimismo, se estimó que estos flujos son fundamentales para financiar los servicios educativos y atención en salud de los hogares receptores. Por lo tanto, las remesas recibidas por los hogares guatemaltecos no solamente tienen un efecto positivo en el bienestar desde la perspectiva del gasto, sino que también generan retornos sobre la inversión en capital humano.

Palabras clave: remesas familiares / bienestar / pobreza / patrones de consumo

\section{Introducción}

El flujo actual de las remesas demuestra cuantitativamente su importancia en cuanto a que financian el sostenimiento de un buen número de guatemaltecos, tanto por el volumen de la población beneficiada, que asciende a 3.7 millones, como por los ingresos promedio para los hogares que reciben estos recursos, \$338 dólares mensuales por hogar (OIM, 2007).

De acuerdo a Terry (2007) las remesas en los países latinoamericanos son una señal de debilidad en la economía, tanto por la incapacidad de la sociedad de generar las oportunidades de desarrollo, como los costos sociales que traen consigo las migraciones masivas, por lo que una economía en desarrollo debe capturar estos flujos de manera 
oportuna y utilizarlos de forma productiva para estar preparados cuando este flujo cese en el largo plazo.

Debido a la influencia que tienen las remesas familiares en los más de tres millones de beneficiarios en Guatemala (OIM, 2007) y la importancia de estos flujos en las economías en vías de desarrollo, investigadores y formuladores de políticas buscan cuantificar los beneficios que pueden traer estos flujos y maximizarlos.

Por lo tanto, el objetivo de esta investigación es aportar evidencia con respecto al posible vínculo que tienen las remesas familiares y la condición de bienestar de los hogares guatemaltecos.

Los objetivos específicos son:

a. Establecer las características de composición, nivel educativo y acceso a servicios básicos de los hogares receptores y no receptores de remesas familiares.

b. Estimar el efecto de las remesas familiares en el gasto per cápita de los hogares.

c. Estimar la magnitud del efecto de las remesas en el nivel de bienestar de los hogares receptores de remesas.

d. Establecer patrones de consumo de los hogares receptores y no receptores de remesas en términos de su nivel de gasto en alimentos, en bienes de consumo, en vivienda, en educación, en salud y en otros bienes.

Para alcanzar los objetivos se utilizó la Encuesta de Condiciones de Vida 2006, que al ser una encuesta de condiciones de vida, no fue diseñada para medir el fenómeno de las remesas familiares y la migración de manera explícita. Por lo tanto, el bienestar de los hogares fue medido de acuerdo a las limitaciones presentadas por la encuesta y de acuerdo a los datos del gasto familiar reportados en la misma.

\section{Las remesas familiares en Guatemala}

En Guatemala, los ingresos por concepto de remesas familiares se han intensificado durante los últimos cinco años. De acuerdo al Departamento de Finanzas, Sector Privado e Infraestructura del Banco Mundial (2006a), el incremento de transferencias unilaterales fue registrado especialmente a partir del año 2001 como consecuencia no solamente de la crisis cafetalera que generó migraciones masivas, sino posiblemente de las mejoras en los sistemas de contabilización de estos flujos, la disminución de los costos de envío en medios formales, así como la liberalización del mercado de divisas a través de la implementación de la Ley de Libre Negociación de Divisas por parte del Banco de Guatemala (Decreto 94-2000 del Banco de Guatemala).

Para 2007, de acuerdo a la CEPAL (s.f.:134), "la economía guatemalteca creció un 5,6\%, lo que obedeció al dinamismo del consumo privado, impulsado por un elevado flujo de remesas familiares (12,5\% del PIB)", lo que equivaldría a casi el $60 \%$ del valor total de las exportaciones del país (FOMIN, 2007).

El flujo actual de las remesas demuestra cuantitativamente su importancia en cuanto a que financian parcialmente el sostenimiento de un buen número de guatemaltecos, tanto por el 
volumen de la población receptora de remesas beneficiada -que asciende a 3.7 millonescomo por los ingresos promedio para los hogares que perciben estos recursos, US\$338 mensuales (Q.2,240), que resultan superiores al ingreso mensual mínimo en todo el país (Q.1,503.50 para trabajo no agrícola y Q.1,457.00 para trabajo agrícola, según el Acuerdo Gubernativo No. 625-2007).

La OIM reportó que en 2007 un 48.8\% de las remesas se destinaron al consumo (consumo familiar en alimentos, ropa, zapatos y los gastos para la adquisición de mobiliario, equipo y otros gastos personales), el 15.2\% al consumo intermedio (inversión en medios de producción), el 22.7\% a la inversión y ahorro, y el 13.4\% a la inversión social (salud y educación).

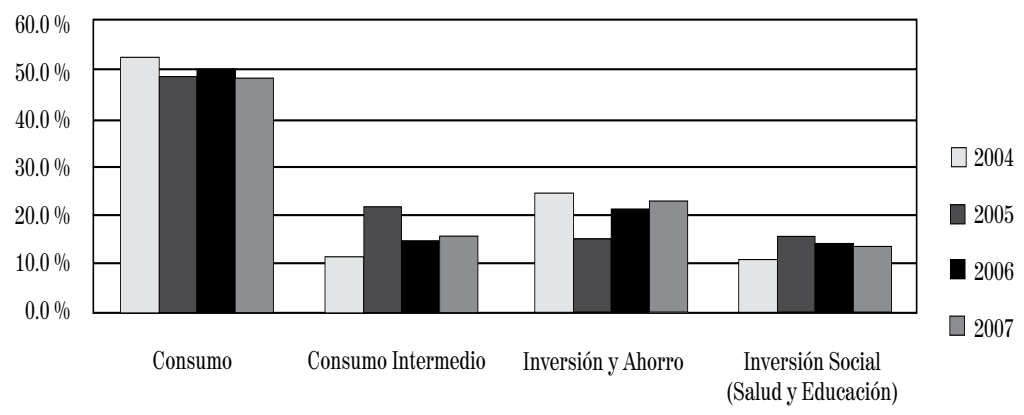

Fuente: Elaboración propia con datos de OIM (2006)

Ilustración 1. Destino de las remesas familiares. Período de 2004 a 2007.

\section{Marco teórico}

Existen diversos enfoques o teorías que abordan la medición del bienestar; entre ellos el enfoque utilitarista, el de necesidades básicas insatisfechas, el Índice de Desarrollo Humano, y el Agregado de Ingreso y Consumo. A continuación se presenta la teoría relacionada con la medición del bienestar a través del Consumo.

La medición del agregado de consumo de los hogares permite definir un parámetro de comparación entre los hogares. El modelo aplicado en este estudio utiliza esta medida, pues a partir de ésta se establecen las líneas de pobreza general y extrema que ayudan a identificar la condición de bienestar de los hogares.

\section{a. La pobreza}

La pobreza es un fenómeno socio económico complejo que no solamente se limita a la falta de ingresos, sino a la privación de las oportunidades para acceder al desarrollo humano. Los pobres dependen de un conjunto de activos que les permita el acceso a mejores oportunidades, como capital humano, activos físicos, financieros y capital social (SEGEPLAN, 2001).

Para la medición de la pobreza es necesario: definir una medida de bienestar que refleje las condiciones de vida de las personas, definir una medida de comparación y clasificación de 
la unidad de medida (hogares o individuos) de acuerdo a su nivel de bienestar, y determinar un indicador que permita la agregación de los individuos en una medida de pobreza.

Las medidas de bienestar comúnmente utilizadas para el estudio de pobreza son: las Necesidades Básicas Insatisfechas (NBI), el Agregado de Ingreso, el Agregado de Consumo y el Índice de Desarrollo Humano (IDH).

Cuadro 1. Principales medidas de bienestar

\begin{tabular}{|c|c|c|}
\hline Medida de bienestar & Ventajas & Desventajas \\
\hline $\begin{array}{l}\text { Necesidades } \quad \text { Básicas } \\
\text { Insatisfechas (NBI): } \\
\text { Insatisfacción o ausencia } \\
\text { de alguna necesidad. }\end{array}$ & $\begin{array}{l}\text { Datos relativamente fáciles } \\
\text { de obtener. } \\
\text { Resultados con un alto nivel } \\
\text { de desagregación geográfica } \\
\text { ajustable a cada país }\end{array}$ & $\begin{array}{l}\text { Periodicidad de la } \\
\text { información censal. } \\
\text { Componentes limitados. } \\
\text { No cuenta con un indicador } \\
\text { agregado de bienestar } \\
\text { ampliamente aceptado. }\end{array}$ \\
\hline $\begin{array}{lcr}\text { Agregado } & \text { del } & \text { Ingreso: } \\
\text { Ingresos } & \text { del } & \text { hogar, } \\
\text { expresado } & \text { en } & \text { moneda } \\
\text { local per cápita. } & \end{array}$ & $\begin{array}{l}\text { Puede relacionarse con } \\
\text { medidas macroeconómicas. } \\
\text { Medida clara y de fácil } \\
\text { comprensión. } \\
\text { Captura cambios recientes } \\
\text { en los hogares. }\end{array}$ & $\begin{array}{l}\text { Subestimación por posibles } \\
\text { confusiones con ingresos } \\
\text { laborales. } \\
\text { Sensible a cambios } \\
\text { temporales (sector agrícola } \\
\text { / informal). } \\
\text { Posible renuencia a dar } \\
\text { información. }\end{array}$ \\
\hline $\begin{array}{l}\text { Agregado de Consumo: } \\
\text { Valor del consumo del } \\
\text { hogar, expresado en } \\
\text { moneda local per cápita. }\end{array}$ & $\begin{array}{l}\text { Tiende a uniformizar } \\
\text { situaciones transitorias. } \\
\text { Anuencia a brindar } \\
\text { información. } \\
\text { Provee información para } \\
\text { el cálculo de líneas de } \\
\text { pobreza. }\end{array}$ & $\begin{array}{l}\text { Periodicidad de encuestas } \\
\text { de esa naturaleza. } \\
\text { Es más costosa la obtención } \\
\text { de la información. }\end{array}$ \\
\hline $\begin{array}{l}\text { Índice de Desarrollo } \\
\text { Humano (IDH): Considera } \\
\text { tres dimensiones: la salud } \\
\text { (esperanza de vida al } \\
\text { nacer), los conocimientos } \\
\text { (alfabetismo y años } \\
\text { promedio de educación) y } \\
\text { el nivel de vida (PIB per } \\
\text { cápita) }\end{array}$ & $\begin{array}{l}\text { Datos relativamente fáciles } \\
\text { de obtener. } \\
\text { Los componentes son } \\
\text { ajustables a cada país. } \\
\text { Permite comparaciones } \\
\text { entre países. }\end{array}$ & $\begin{array}{l}\text { Componentes limitados. } \\
\text { Arbitrariedad de algunos } \\
\text { pesos y rangos. }\end{array}$ \\
\hline
\end{tabular}

Fuente: Mapas de pobreza en Guatemala al 2002. (SEGEPLAN, 2006). 
$\mathrm{Al}$ seleccionar una medida de bienestar se debe tomar en cuenta la disponibilidad de los datos, la definición de pobreza que se utilice y el uso que se quiera hacer de la medida.

En los años 80 tres autores, Foster-Greer-Thorbecke (FGT), desarrollaron un índice para medir tres aspectos fundamentales de la pobreza: la cantidad de pobres que hay en determinada área geográfica, la brecha que existe entre los pobres y la severidad de la pobreza. El índice permite identificar no sólo la heterogeneidad de la pobreza sino la distribución del ingreso al interior de una población considerada como pobre (León, s.f.). El índice FGT de FosterGreer-Thorbecke es expresado por²:

$$
\mathrm{P}_{\alpha}(\mathrm{y} ; \mathrm{z})=\frac{1}{\mathrm{n}} \sum_{\mathrm{i}=1}^{\mathrm{q}} \frac{\mathrm{gi}}{\mathrm{z}}^{\alpha}
$$

Donde $\mathrm{y}=(\mathrm{y} 1, \mathrm{y} 2, \ldots, \mathrm{y} 3)$ es un vector de ingreso de los hogares en orden creciente y para el que se asume que $\mathrm{z}>0$ es una línea predeterminada de pobreza; gi $=\mathrm{z}-\mathrm{y}_{\mathrm{i}}$ es el déficit del ingreso del i-ésimo hogar; $q=q(y ; z)$ es el número de hogares pobres (que tienen un ingreso no mayor a $\mathrm{z}$ ); $\mathrm{n}=\mathrm{n}(\mathrm{y})$ es el número total de hogares y $\alpha$ es la medida de aversión a la pobreza. A mayor valor de $\alpha$, mayor es el énfasis que el índice hace de los hogares pobres.

De la fórmula anterior se pueden derivar tres medidas de pobreza: incidencia, brecha y severidad de pobreza.

La incidencia de pobreza, $\mathrm{P}_{0,}$ (cuando $\alpha=0$ ) es una medida que corresponde a la proporción de personas que se encuentran en determinada área geográfica cuyo consumo se encuentra por debajo de la línea de pobreza.

La brecha de pobreza, $\mathrm{P}_{1}$ (cuando $\alpha=1$ ) además de considerar el número de pobres, mide qué tan alejadas de la línea de pobreza están las personas. Representa la distancia que hay entre la línea de pobreza y el consumo de los hogares pobres.

La severidad de pobreza, $\mathrm{P}_{2}$, (cuando $\alpha=0$ ) eleva al cuadrado la brecha de consumo de los pobres y está expresada como una proporción de la línea de pobreza. Esta medida sirve también como un indicador de desigualdad entre los pobres. ${ }^{3}$

\section{b. Las remesas familiares y la pobreza}

A pesar de que la evidencia empírica es limitada y poco concluyente, se argumenta que las remesas juegan un papel muy importante para reducir la pobreza en las economías en desarrollo, así como para reducir la incidencia y la severidad de la pobreza. Según Yang y Martínez (citados en Banco Mundial, 2006a), las remesas no solamente parecen reducir la pobreza de los hogares con migrantes, sino que también tienen efectos beneficiosos aún para los hogares que no reciben remesas y que pertenecen a una misma comunidad. 
Las remesas familiares, según el Banco Mundial (2006a), no solamente pueden reducir la pobreza, sino suavizar el consumo, mejorar el acceso a capital de trabajo e incrementar la inversión en capital social (como educación y salud). "En el corto plazo, las remesas afectan el precio de los bienes no comerciables, mientras que en el largo plazo el aumento de ingresos generado por la migración reduce las restricciones de liquidez para invertir en actividades productivas" (PNUD, 2007:92).

Esquivel y Huerta-Pineda (2006), en el estudio del impacto de las remesas en México, citan a Kapur (2004) para explicar que debido a que los migrantes no provienen de los hogares más pobres, sus efectos directos en los grupos más desfavorecidos son limitados y los beneficios en la estructura de la pobreza son de naturaleza indirecta. Adams (2004), utilizando datos de la Encuesta de Condiciones de Vida (ENCOVI) del año 2000, encontró evidencia que sugiere que las remesas tienen un impacto mayor en el alivio de la severidad de la pobreza que en el nivel de pobreza propiamente dicho y tienen poco o ningún impacto en la desigualdad de ingresos.

Por otro lado, Escobar (2006; citado en PNUD, 2007:148) sugiere que "las remesas reducen la desigualdad y la pobreza. No obstante, éstas serían menores si los migrantes no hubieran migrado" debido a que la migración puede implicar una descapitalización tanto de recursos humanos como económicos, así como también existe la posibilidad de que los fondos recibidos simplemente compensen la pérdida de capacidad productiva generada por la ausencia del migrante, por lo que no habrá acumulación de activos generadores de ingreso al destinarse fundamentalmente al consumo del hogar.

En contraste, Székely y Rascón (2005; citados en PNUD, 2007) argumentan que la posible reducción de la pobreza no puede atribuirse a las remesas, así como tampoco es claro el efecto que han tenido las remesas en la reducción de la desigualdad. Pero según Wodon, Urdinola, Gonzales, Ojeda y Siaens (2004; citados en PNUD, 2007:150), en el sur de México "los hogares no pobres tienden a recibir más remesas que los hogares pobres, lo que puede implicar que las remesas incrementen la desigualdad”.

En cuanto al gasto de los hogares, Cohen (2005) dice que las remesas familiares destinadas principalmente al consumo distorsionan la economía local, y crean conflictos y desigualdades locales. Asimismo, señala que la dependencia de los hogares a estos flujos provoca que más miembros del hogar busquen migrar a destinos en el extranjero. De acuerdo al autor, los retornos monetarios de estos flujos son relativamente bajos, pues un porcentaje mínimo es utilizado para ahorro e inversiones productivas que puedan generar efectos multiplicadores del ingreso, así como creación de empleos.

Debido a que las preferencias de los hogares son distintas aún no se ha logrado determinar qué genera más beneficios, si invertir o consumir. Pero desde la perspectiva de bienestar, trae más ganancias invertir un dólar que gastarlo (Banco Mundial, 2006a), por lo que es muy importante que el hogar tenga incentivos para ahorrar o invertir el dinero recibido por remesas y de ésta forma maximizar los beneficios de estos flujos. 


\subsection{Modelos de Adams $(2004,2005)$}

\section{a. Remesas y pobreza}

Para analizar el efecto de las remesas familiares en los hogares es necesario crear una medida que sirva como base de comparación de cuál sería la situación de bienestar de los hogares si no recibieran remesas.

Adams (2004) utiliza un modelo econométrico lineal que busca predecir o estimar cuál sería el gasto per cápita de los hogares receptores de remesas familiares si no recibieran este ingreso y de esta forma cuantificar la variación del gasto cuando se incluyen estos flujos en el presupuesto familiar.

Hay tres razones por las que Adams utiliza el gasto per cápita del hogar en vez del ingreso familiar. Primero, el propósito de la medición es estimar el efecto de las remesas en el bienestar, y el consumo es una medida más estable en comparación con el ingreso. Segundo, en países en vías de desarrollo como Guatemala, los gastos son más sencillos de medir por la dificultad que involucra medir y definir el ingreso de aquellos que son auto empleados en la agricultura, que representan un gran porcentaje de la fuerza laboral. Tercero, la medición de la línea de pobreza que será utilizada en el estudio para categorizar a los hogares está basada en información del gasto del hogar.

Debido a que las decisiones del hogar están condicionadas por una serie de variables geográficas, políticas, sociales y económicas, el modelo de Adams supone que el gasto per cápita del hogar (excluyendo las remesas) puede ser estimado en función de un conjunto de variables características del hogar, tales como: variables de composición del hogar, educación de los miembros del hogar, su acceso a servicios, la ubicación geográfica (área y región) y el grupo étnico al que pertenece.

\section{b. Remesas, gasto del hogar e inversión}

Además de determinar qué efecto han tenido las remesas directamente sobre el gasto per cápita de los hogares, Adams (2005) utiliza variables socio demográficas de los hogares para determinar cuál ha sido el efecto que han tenido las remesas en los patrones de consumo de los hogares y comparar así sus decisiones de consumo con aquellos hogares que no reciben remesas.

Al comparar la conducta de gasto de los hogares con diferentes niveles de ingreso, se deben tomar en cuenta varios factores socioeconómicos y de ubicación además del gasto. De acuerdo a Adams (2004), las diferencias observadas en la conducta de gasto pueden deberse, por ejemplo, a las diferencias en la composición del hogar (tamaño del hogar, número de hijos, etc.), educación, área urbana o rural, región geográfica, o si el hogar recibe o no remesas familiares. 


\section{c. Muestra}

Se utilizaron datos recolectados por la ENCOVI 2006 en el período de marzo a septiembre de 2006. El universo de la encuesta se divide a nivel nacional por área urbana y rural en 22 dominios de estudio. Cada uno corresponde a los 22 departamentos del país con información de 13,693 hogares distribuidos en todo el territorio nacional. El análisis permitió un nivel de desagregación válido para todo el país, por región y por área (urbana y rural).

\section{Resultados}

A continuación se presentan los resultados obtenidos de la aplicación del modelo de Adams a la Encuesta de Condiciones de Vida (ENCOVI) 2006 para establecer el efecto que las remesas familiares tienen en el bienestar de los hogares.

\subsection{Características de los hogares que reciben remesas familiares}

Del total de hogares encuestados, $88.65 \%(12,132)$ de los hogares reportó no recibir remesas familiares mientras que el 11.36\% $(1,554)$ sí reciben remesas del exterior. En relación a las características de los hogares, como se muestra a continuación, los resultados sugieren que los hogares que reciben remesas son distintos a los hogares que no reciben remesas.

\section{a. Composición del hogar}

En relación a la composición de los hogares, los que reciben remesas son en promedio diferentes a los hogares que no las reciben en varias dimensiones (ver Ilustración 2).

El número de integrantes de los hogares receptores es menor debido a la migración de algunos de sus miembros. El fenómeno de la migración se ve reflejado directamente en el número de hombres mayores de 15 años que conforman los hogares que reciben remesas debido a que la mayoría de los migrantes son los hombres jefes de hogar ${ }^{4}$ que dejan atrás a sus familias.

Los hogares receptores de remesas están conformados por un número mayor de mujeres mayores de 15 años, lo que sugiere que los beneficiarios de estos flujos son mujeres. Asimismo, el número de niños menores de 5 años es menor en los hogares receptores, lo que puede estar relacionado con el hecho que es el jefe de hogar el migrante que reside en el exterior. 


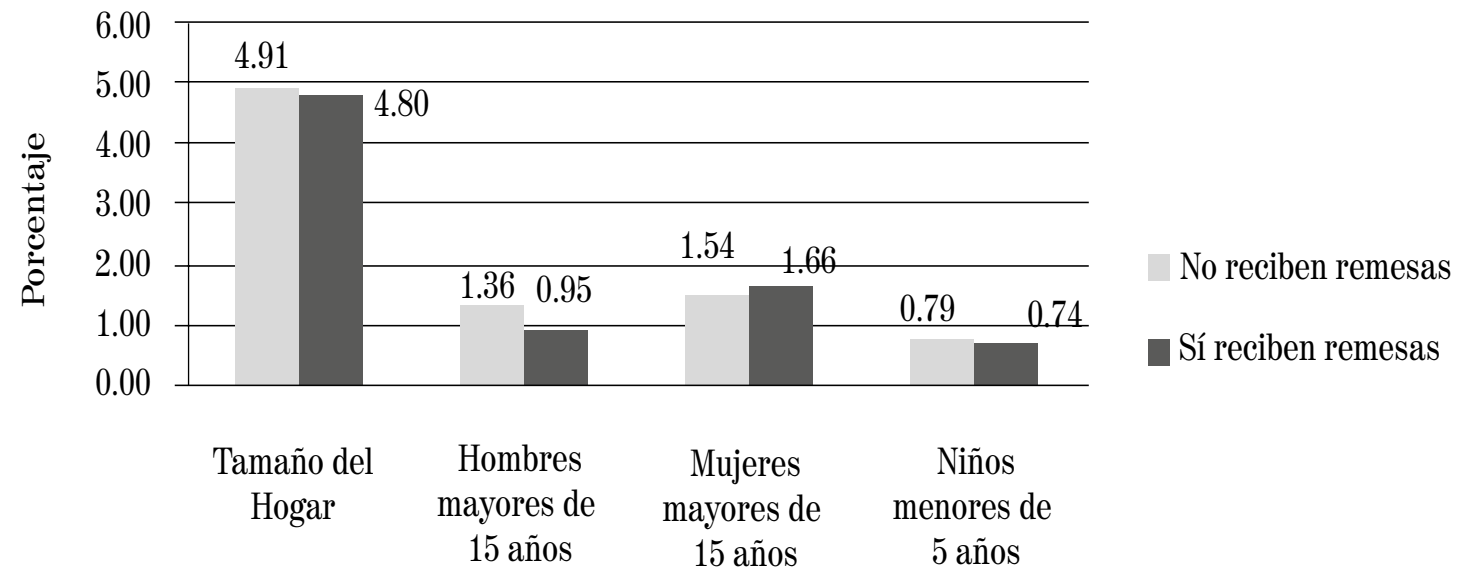

Ilustración 2. Características de los hogares por su composición

Nota: $\mathrm{N}=13,686$ hogares. Todos los valores son medias ponderadas y significativas al $5 \%$. Fuente: Encuesta de Condiciones de Vida (ENCOVI), (INE, 2006).

\section{b. Educación}

Respecto al nivel educativo de los miembros del hogar, los miembros mayores de 15 años que pertenecen a los hogares que reciben remesas parecen tener en promedio menor educación en el nivel primario y superior (diversificado y universitario) en comparación con los hogares que no reciben remesas. Por lo que en cuanto a sus características educativas, las personas que reciben remesas son menos educadas a nivel primario y superior.

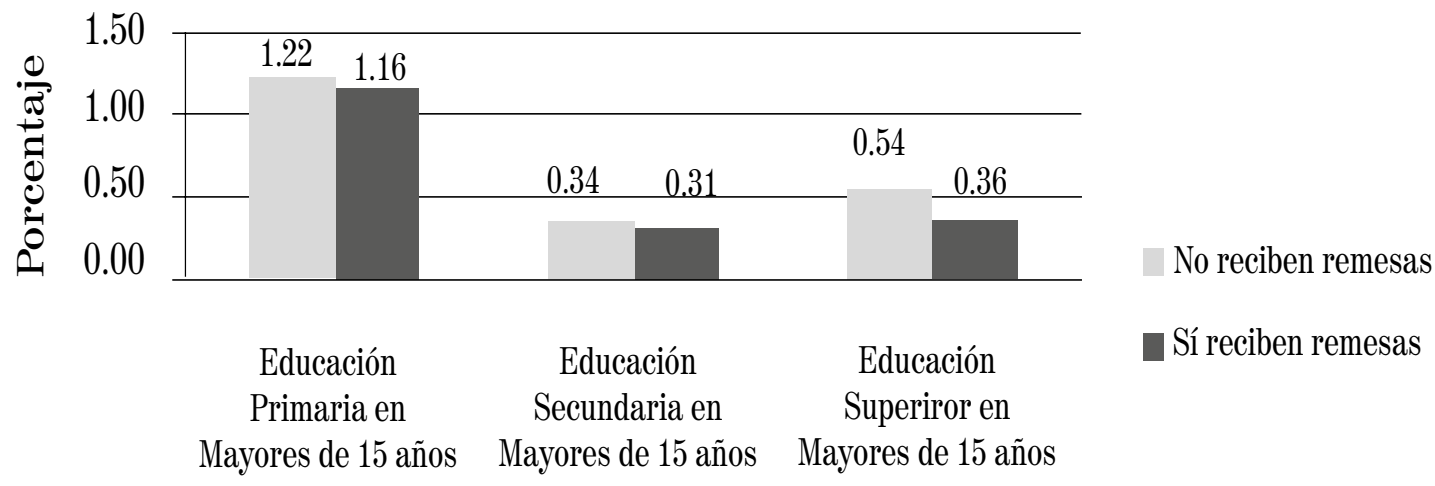

Ilustración 3. Características de los hogares por su nivel académico Nota: $\mathrm{N}=13,686$ hogares. Todos los valores son medias ponderadas y significativas al $5 \%$. Fuente: Encuesta de Condiciones de Vida (ENCOVI), (INE, 2006). 


\section{c. Acceso a servicios básicos}

Los resultados muestran que de los hogares que reciben remesas un $89 \%$ cuenta con el servicio de electricidad y un 86.33\% tiene acceso a agua entubada. Por otro lado, los hogares que no reciben remesas tienen acceso al servicio eléctrico en un 78.92\%, mientras que al servicio de agua un $92.54 \%$ tiene acceso.

Al cuantificar el acceso a los servicios por área, de los hogares que no reciben remesas en el área urbana el 92.19\% tiene acceso a electricidad y el $97.12 \%$ a agua entubada. Mientras que de los que reciben remesas, el $96.18 \%$ tiene acceso a servicio de electricidad y el $96.65 \%$ al servicio de agua.

En el área rural, de los hogares que no reciben remesas, tienen acceso a electricidad y agua potable un 68.58\% y 87.75\% respectivamente, y de los hogares que sí reciben remesas, el acceso es de $85.62 \%$ a electricidad y del $80.88 \%$ al agua entubada.

4.2. Efecto de las remesas en los niveles de bienestar

A continuación se presentan los resultados obtenidos al aplicar el Modelo de Adams para calcular el efecto de las remesas en los niveles de pobreza de los hogares.

Para la estimación del efecto de las remesas entre hogares, es decir, al comparar los hogares receptores con aquellos que no reciben remesas, de acuerdo a su clasificación de pobreza se obtiene que los hogares receptores de remesas no pobres gastan en promedio un $1.93 \%$ más, mientras que el aumento en el gasto de los hogares pobres y pobres extremos es de un $2.25 \%$ y $7.41 \%$.

Cuadro 2. Efecto de las remesas en el gasto per cápita anual entre hogares Por rango de pobreza (En quetzales)

\begin{tabular}{lrcc}
\hline Gasto de los hogares & No pobres & Pobres & Pobres extremos \\
\hline Que no reciben remesas & Q $17,413.24$ & Q 4,803.02 & Q 2,496.85 \\
Que sí reciben remesas & Q 17,748.73 & Q 4,910.93 & Q 2,681.81 \\
Efecto de las remesas & $\mathbf{Q ~ 3 3 5 . 4 9}$ & $\mathbf{Q ~ 1 0 7 . 9 1}$ & $\mathbf{Q ~ 1 8 4 . 9 6}$ \\
\hline
\end{tabular}

* Gasto estimado. Fuente: ENCOVI 2006 (INE, 2006).

Para estimar el efecto que han tenido las remesas en el hogar receptor de acuerdo a su clasificación de pobreza, se hace evidente que las remesas tienen un mayor efecto en los hogares no pobres. Al recibir las remesas el hogar no pobre incrementa su gasto per cápita anual en un 15.56\%, mientras que para los hogares en situación de pobreza y extrema pobreza recibir remesas solamente representa un aumento en su gasto del $3.26 \%$ y $4.06 \%$ respectivamente. 
Cuadro 3. Efecto de las remesas en el gasto per cápita anual en los hogares receptores de remesas familiares

Por rango de pobreza

(En quetzales)

\begin{tabular}{lccc}
\hline & No pobres & Pobres & Pobres extremos \\
\hline Excluyendo las remesas* & Q $15,358.25$ & Q $4,755.85$ & Q $2,576.30$ \\
Incluyendo las remesas & Q $17,748.73$ & Q $4,910.93$ & Q $2,681.81$ \\
Efecto de las remesas & $\mathbf{Q ~ 2 , 3 9 0 . 4 8}$ & $\mathbf{Q ~ 1 5 5 . 0 8}$ & $\mathbf{Q ~ 1 0 5 . 5 1}$ \\
$\begin{array}{l}\text { Aumento porcentual del } \\
\text { gasto }\end{array}$ & $\mathbf{1 5 . 5 6 \%}$ & $\mathbf{3 . 2 6} \%$ & $\mathbf{4 . 0 6 \%}$ \\
\hline
\end{tabular}

* Gasto estimado. Fuente: ENCOVI 2006 (INE, 2006).

Adicionalmente, se puede ver que la incidencia, la brecha y la severidad de la pobreza disminuyen con la presencia de remesas familiares. Para 2006 se estimaba que la pobreza en Guatemala alcanzaría a un $56.75 \%$ de la población si no recibieran remesas, por lo que se puede atribuir a las remesas familiares una disminución en la incidencia de pobreza de un $0.898 \%$. Por otro lado, al estimar la brecha de pobreza se calcula que sería de un $36.21 \%$, pero al recibir remesas ésta disminuye a un $35.57 \%$ (un 0.648\%) en la brecha, y en cuanto a la severidad de la pobreza las remesas generan una disminución de un $0.841 \%$ y pasa de $17.55 \%$ (al excluir las remesas) a un $16.71 \%$.

Cuadro 4. Efecto de las remesas en la pobreza, Guatemala (2006)

(Porcentajes)

\begin{tabular}{lccc}
\hline \multicolumn{1}{c}{ Gogares } \\
Gasto per cápita promedio & $\begin{array}{c}\text { No reciben } \\
\text { remesas } \\
\mathbf{( 1 )}\end{array}$ & $\begin{array}{c}\text { Reciben } \\
\text { remesas } \\
\mathbf{( 2 )}\end{array}$ & $\begin{array}{c}\text { Variación } \\
\text { Porcentual }\end{array}$ \\
\hline Pobreza & $56.75 \%$ & $55.86 \%$ & $0.898 \%$ \\
Brecha de pobreza & $36.21 \%$ & $35.57 \%$ & $0.648 \%$ \\
Severidad de pobreza & $17.55 \%$ & $16.71 \%$ & $0.841 \%$ \\
\hline
\end{tabular}

Notas: La columna (1) mide la situación de pobreza de todos los hogares si se excluyen las remesas. La columna (2) mide la situación de pobreza al incluir las remesas. El cálculo de pobreza se calculó en base a la línea de pobreza del Instituto de Estadística Nacional (INE) de Q. 6,574.00 por persona al año.

Fuente: ENCOVI 2006. 
Es decir que estos flujos tienen un mayor impacto en la disminución de la incidencia de pobreza y su severidad, y menor en la disminución de la brecha entre los pobres.

\section{a. Remesas y el gasto per cápita anual de los hogares}

Las remesas familiares aumentan el nivel de gasto de los hogares. Los hogares guatemaltecos que reciben remesas gastan un 7.96\% más que aquellos que no las reciben.

Los resultados obtenidos demuestran que si el hogar receptor no tuviera acceso a estos ingresos, el gasto per cápita anual del hogar sería equivalente a Q11,427.50 mientras que el gasto real observado es de Q13,017.91. Ello significa que su gasto, en promedio, aumenta un 13.92\% (equivalente a Q1,590.41) al recibir las remesas, por lo que el efecto neto de las remesas es de un $2.73 \%$.

Al desagregar el efecto de las remesas según el área de residencia de los hogares, se obtiene que los hogares del área urbana que reciben remesas gastan en promedio un $14.46 \%$ más que los hogares que no las reciben. Para los hogares receptores de esta área, esos recursos han significado la posibilidad de aumentar su gasto per cápita anual en un $12.40 \%$ (equivalente a Q2,048.47).

Respecto a los hogares del área rural, los resultados muestran que los receptores gastan en promedio un $33.70 \%$ más que aquellos que no las reciben. En cuanto al efecto que han tenido estos flujos específicamente en los hogares receptores, se puede cuantificar que su gasto per cápita anual ha aumentado en un 16.94\% (equivalente a Q.1,275.35).

El efecto de estos recursos adicionales en los hogares, por lo tanto, es mayor en el nivel de gasto de los hogares que residen en el área rural, por lo que en comparación con los hogares urbanos, éstos tienen una mayor dependencia de estos flujos.

\subsection{Patrón de consumo de los hogares}

Para establecer el patrón de consumo de los hogares se calculó la propensión media y marginal de consumo de seis bienes. Mientras que la propensión media explica cuánto destina el hogar al gasto de determinado bien respecto a su gasto total, la propensión marginal explica cuánto gasta el hogar en un bien al recibir un quetzal adicional en su ingreso.

Para 2006, de acuerdo a la estimación de la propensión media de consumo, los hogares que recibían remesas destinaban un $43.5 \%$ de sus gastos totales al consumo de alimentos, el $18.7 \%$ al consumo de bienes de consumo y durables, el 12.7\% al gasto en vivienda, el 17.8\% al gasto en otros bienes (servicios para el hogar) y un 7.30\% a la inversión social (salud y educación).

Por otro lado, las propensiones marginales del consumo muestran un interesante contraste en las decisiones de gasto entre los hogares que reciben remesas y los que no las reciben. Ambos tipos de hogares destinan más del 35\% de su gasto total al consumo de alimentos. Sin embargo, al recibir un quetzal adicional, los hogares que reciben remesas gastan un 5.40\% 
menos en alimentos. Este resultado es consistente con el presentado por Adams (2004) en el que obtiene que la propensión marginal en alimentos es menor para los receptores de remesas, lo que sería consistente con la hipótesis de que los hogares que perciben remesas son en promedio más ricos que los no receptores.

Los hogares que reciben remesas destinan, por cada quetzal adicional que reciben en sus ingresos, un $4.60 \%$ en salud y $13.3 \%$ en educación, mientras que los hogares que no reciben remesas destinan un 3.02\% y 5.25\% respectivamente a estos rubros. Para ambos grupos de hogares casi el 40\% del presupuesto está destinado al consumo de alimentos.

Respecto al consumo en bienes durables y de consumo, los hogares que reciben remesas gastan más al margen que los hogares que no reciben remesas y esto puede estar relacionado con una mayor compra de activos para el hogar, así como también con el gasto para el pago por servicios de electricidad y agua, pues como se discutiera anteriormente estos hogares tienen mayor acceso a ambos servicios.

Contrario a lo esperado y presentado por Adams, la propensión marginal del gasto en vivienda de los hogares que reciben remesas es menor en comparación con los hogares que no reciben remesas. Este resultado puede estar relacionado con la forma de medición del gasto en vivienda, pues éste solamente considera los gastos del hogar para el pago de alquiler de la vivienda actual y no toma en cuenta posibles gastos en mejoras a la vivienda ni otros gastos de construcción que sean financiados por las remesas familiares.

\section{Discusión}

\section{a. Las remesas y el bienestar de los hogares}

Los resultados obtenidos demuestran que las remesas familiares tienen un impacto positivo en el bienestar de los hogares guatemaltecos en términos de su gasto per cápita, así como también en la disminución de las tres dimensiones de la pobreza: el porcentaje de pobres, la brecha de pobreza y la severidad.

Al comparar el gasto entre hogares, es decir, los hogares que reciben remesas y los que no, los resultados muestran que el bienestar de los hogares receptores de remesas es mayor, pues generan un aumento en el gasto per cápita de los hogares que las reciben en un 7.96\%. Por otro lado, al estimar el aumento del gasto en los hogares receptores, se encontró que al recibir remesas el gasto aumenta en un promedio de $13.92 \%$.

La disminución de la pobreza relacionada con las remesas está por debajo de un 1\%, lo que puede estar explicado por el hecho de que los mayores beneficiarios de estos flujos son los hogares clasificados como no pobres (o que están por encima de la línea de pobreza). Consecuentemente, el gasto de los hogares receptores no pobres es mayor en un 18.24\% en comparación con los hogares que no reciben remesas, mientras que para los hogares que están debajo de la línea de pobreza y extrema pobreza, las remesas solamente representan un aumento de $2.25 \%$ y $7.41 \%$ respectivamente. 


\section{b. Comportamiento de gasto de los hogares}

Respecto al patrón de gasto de los hogares, es importante considerar que los hogares que reciben remesas son distintos (en promedio) a los hogares que no las reciben y por lo tanto toman decisiones de consumo de una manera distinta a los hogares que no reciben estos flujos de ingreso.

Al estimar las propensiones marginales de consumo, se obtiene que ambos grupos de hogares destinan una buena parte de los gastos para el consumo de alimentos y bienes de consumo de primera necesidad. Sin embargo, al comparar estas propensiones marginales, mientras que los hogares que no reciben remesas destinan un 39.28\% para los alimentos, los hogares que sí reciben remesas destinan solamente un $37.16 \%$ por cada quetzal adicional que reciben en su ingreso.

Por otro lado, los hogares que reciben remesas gastan más (en términos marginales) en inversión social (salud y educación) que los hogares que no reciben remesas, lo cual revela el potencial de desarrollo de las remesas. El comportamiento de gasto de los hogares que tienen migrantes genera expectativas sobre los retornos que podría tener esa inversión en capital humano en el largo plazo. Según Adams (2004), mientras que los alimentos son un bien de consumo, los gastos en salud y educación corresponden a inversión social en capital humano que en el largo plazo podría generar desarrollo.

Con relación al gasto en vivienda de los hogares que reciben remesas, hay expertos del Banco Mundial $^{5}$ que afirman que el gasto en vivienda de los hogares que reciben remesas debe ser mayor que el gasto de los hogares que no reciben remesas. Es importante mencionar que esto puede estar relacionado directamente con la medida utilizada por el INE y el cálculo del gasto (consumo) agregado del hogar. La medición del gasto en este rubro solamente involucra el gasto de los hogares para el alquiler o renta y no toma en cuenta las posibles mejoras que el hogar pueda realizar a su vivienda con las remesas. La encuesta incluye un capítulo que captura los gastos en mejoras de vivienda, la medida agregada que se utiliza en este estudio no la incluye.

\section{Conclusiones}

En lo que se refiere a los hogares guatemaltecos receptores de remesas, son los hombres jefes de hogar los que mayormente constituyen el grupo migrante. Éstos cuentan con un nivel educativo mayor que el resto de miembros en la familia. Debido a lo anterior, los resultados confirman que los beneficiarios de estos flujos son en su mayoría mujeres y que, en términos relativos, su nivel educativo primario y superior es menor.

En el caso de Guatemala, las remesas familiares tienen un efecto positivo en los niveles de bienestar de las familias receptoras en comparación con los que no reciben remesas. Al cuantificar el aumento del gasto de los hogares receptores de remesas se concluye que estos hogares gastan un 7.96\% más que los hogares no receptores, lo que equivale a Q959.47. 
$\mathrm{Al}$ determinar el efecto de las remesas en los hogares receptores de remesas, se concluye que al recibir estos flujos como ingresos adicionales el hogar receptor aumenta su gasto un promedio de $13.92 \%$, lo que equivale a Q. 1,590.41. El efecto de las remesas es mayor para los hogares receptores no pobres que registran un aumento en su gasto de un $15.56 \%$, mientras que el efecto para los hogares pobres y extremadamente pobres es solamente un aumento de $3.26 \%$ y $4.06 \%$ respectivamente.

Las remesas familiares disminuyen la incidencia, la brecha y severidad de la pobreza. El presente estudio demuestra, para el caso de Guatemala, que los tres índices de pobreza (incidencia, brecha y severidad) disminuyeron por debajo del 1\% con la presencia de estos flujos en el año 2006. Si bien los ingresos por concepto de remesas familiares se han intensificado durante los últimos cinco años y representaron más del 10\% del PIB, los resultados muestran que las remesas aún se concentran en los hogares menos pobres del país y el beneficio para los hogares más pobres está por debajo de un 5\%.

Los resultados obtenidos demuestran que los hogares receptores de remesas gastan marginalmente un 5.43\% menos para el consumo de alimentos y destinan más recursos para inversión social (salud y educación) equivalente a un 7.30\% más que los hogares no receptores. Por lo tanto, las remesas son fundamentales para financiar los servicios educativos y atención en salud. Se puede concluir que estos flujos no solamente tienen un efecto positivo en el bienestar desde la perspectiva del gasto, sino que también genera retornos sobre la inversión en capital humano, pues la inversión en salud y educación incide favorablemente en el mediano y largo plazo.

\section{Notas}

1 Si desea mayor información sobre la metodología aplicada comunicarse con la autora.

2 Expuesto por León, E. (s.f.) en Dinámica de la pobreza de los hogares en México: 2001-2002.

3 Definiciones de P0, P1 y P2 obtenidas de Mapas de pobreza en Guatemala al 2002. (SEGEPLAN, 2006).

4 Para el 2007, la OlM reportó que en el extranjero residen 1,482,247 personas, de las cuales el $72 \%$ corresponde a hombres.

5 Ver Banco Mundial (2006b) y Fajnzylber y López (2007).

\section{Referencias bibliográficas}

ADAMS, R. (2005) Remittances, Household Expenditure and Investment in Guatemala. World Bank Policy Research Working Paper 3532. Washington, D.C.:The World Bank. ADAMS, R. (2004) Remittances and Poverty in Guatemala. World Bank Policy Research Working Paper 3418. Washington, D.C.: The World Bank.

BANCO MUNDIAL (2006a) Global Economic Prospects 2006: Economic Implications of Remittances and Migration. Capítulo 5. (Versión Electrónica) Disponible en: www. worldbank.org/prospects/gep2004. Consultada:

BANCO MUNDIAL (2006b) Análisis del corredor de remesas Estados Unidos-Guatemala. Departamento de Finanzas, Sector Privado e Infraestructura Región de Latinoamérica y el Caribe del Banco Mundial.

COHEN, J. (2005) "Remittance Outcomes and Migration: Theoretical Contests, Real 
Opportunities". Studies in Comparative International Development, Spring 2005, Vol. 40, No. 1, pp. 88-112.

COMISIÓN ECONÓMICA PARA AMÉRICA LATINA Y EL CARIBE (Sin fecha). Balance preliminar de las Economías Latinoamericanas 2007 - Guatemala (Versión electrónica). Disponible en: www.eclac.cl/publicaciones/xml/3/31993/Guatemala.pdf. Consultada: 9 de octubre de 2007.

ESQUIVEL, G. \& HUERTA-PINEDA, A. (2006) Remittances and Poverty in Mexico: A Propensity Score Matching Approach. Working Paper. México: Colegio de México. Presentación Power Point (Versión electrónica). Disponible en: www.dallasfed.org/news/ research/2005/05us-mexico esquivel.pdf. Consultada: 25 de agosto de 2007.

FAJNZYLBER, P. \& LÓPEZ, H. (2007) Cerca de casa: Impacto de las remesas en el desarrollo de América Latina. Presentación del Banco Mundial "Corredor de Remesas Impacto en el desarrollo" realizada en Guatemala.

INSTITUTO NACIONAL DE ESTADÍSTICA (2006) Encuesta de condiciones de Vida ENCOVI 2006, marzo - septiembre 2006: Guatemala: INE.

LEÓN, E. (sin fecha) Dinámica de la pobreza de los hogares en México: 2001-2002. (Versión electrónica). Disponible en: catarina.udlap.mx/u_dl_a/tales/documentos/lec/ leon_b_e/capitulo2.pdf. Consultada: 25 de noviembre de 2008.

ORGANIZĀCIÓN INTERNACIONAL PARA LAS MIGRACIONES (2006) "Encuesta sobre Remesas 2006 Inversión en Salud y Educación”. Cuadernos de Trabajo sobre Migración No. 23

ORGANIZACIÓN INTERNACIONAL PARA LAS MIGRACIONES (2007) "Encuesta sobre Remesas 2007. Perspectiva de Género". Cuadernos de Trabajo sobre Migración No. 24

PROGRAMA DE LAS NACIONES UNIDAS PARA EL DESARROLLO (2007) Informe sobre Desarrollo Humano México 2006-2007. Migración y Desarrollo Humano. México, D.F.: PNUD.

SECRETARÍA DE PLANIFICACIÓN Y PROGRAMACIÓN DE LA PRESIDENCIA - SEGEPLAN (2006). Mapas de pobreza en Guatemala al 2002. Volumen I, Guatemala: Gobierno de Guatemala.

TERRY, D. (2007) Las remesas a Latinoamérica alcanzarán los 72.000 millones de dólares en 2007. Disponible en: http://www.eleconomista.es/empresas-finanzas/ noticias/183351/01/70/Las-remesas-a-Latinoamerica-alcanzaran-los-72000-millones-dedolares-en-2007.html. Consultada: 13 de agosto de 2007. 